\title{
TRENDS IN REVASCULARIZATION FOR CRITICAL LIMB ISCHEMIA OF LOWER LIMBS
}

Ravikumar B. L1 ${ }^{1}$ Jose V. Francisco ${ }^{2}$

\section{HOW TO CITE THIS ARTICLE:}

Ravikumar B. L, Jose V. Francisco. "Trends in Revascularization for Critical Limb Ischemia of Lower Limbs". Journal of Evolution of Medical and Dental Sciences 2014; Vol. 3, Issue 30, July 28; Page: 8532-8536, DOI: $10.14260 /$ jemds/2014/3082

ABSTRACT: OBJECTIVE: To study the trends in revascularization procedures done for critical limb ischemia (CLI) of lower limbs. MATERIALS AND METHODS: Total of 166 revascularization procedures done for CLI by a single vascular surgeon between June 2010 and May 2014 at Kempegowda Institute of Medical Sciences Bangalore. Both endovascular and open bypass procedures for lower limb ischemia were included. This retrospective study was conducted to evaluate the outcomes of the procedures and to see the trends in the management of CLI of lower limb. Only elective cases were included in the study. Emergency revascularization procedures for acute limb ischemia and those below 45 years suspected to be thromboangiitis obliterans were excluded STUDY PERIOD: Review of 4 year experience from June 2010 to May 2014. Follow up period was 24 months. Patients were predominantly male (94\%), of the $5^{\text {th }}$ and $7^{\text {th }}$ decade of life (Median age 60 years).All patients presented with chronic lower limb ischemia with critical limb ischemia. Commonest presentation was disabling claudication, rest pain with ulcerations and digital gangrene. Co morbid conditions included diabetes mellitus, smoking history, hypertension, hyperlipidemia, cardiac disease. Total procedures done: Open- 104, Endovascular- 62. Open procedures: Aorto-femoral (21) femoro-femoral (33) femoropopliteal (50). Primary endovascular revascularization procedures angioplasty alone (53\%) angioplasty + stenting (47\%). Complication rate was significantly higher and the mean hospital stay was significantly longer with open surgery (15\%, 10 days) compared with endovascular surgery $(0.08 \%$, 4days) $(\mathrm{P}<0.05)$. Furthermore the number of endovascular revascularization procedures done significantly increased from $6 \%$ in the first period (June 2010-May 2011) to 61\% in the last period (June2013-May2014). CONCLUSIONS: Endovascular procedures for CLI have largely replaced open surgical procedures. Angioplasty is a feasible, safe, and effective procedure with less morbidity and can be the procedure of choice for the primary and secondary treatment of CLI. Open bypass surgery can be reserved for lesions technically unsuitable for endovascular procedures and patients who do not demonstrate clinical improvement after angioplasty.

KEYWORDS: Revascularisation, Critical limb Ischemia, Endovascular.

INTRODUCTION: Chronic lower limb ischemia is a common condition. The incidence of patients presenting with critical limb ischemia (CLI) has increased over the last decade. Over 25\% of CLI patients will require major amputation. However with the availability of reconstructive surgical procedures, the limb salvage rates have increased and amputation rates decreased. ${ }^{1}$

This amputation rate has further declined with the introduction of newer endovascular revascularization methods which have shown increasing success in limb salvage and long term palliation of disabling claudication. 


\section{ORIGINAL ARTICLE}

AIMS AND OBJECTIVES: This study was undertaken to study the trends in revascularization procedures for CLI in chronic lower limb ischemia at our institute.

METHODS: This retrospective study was conducted through the review of records of all elective revascularization procedures done for patients with chronic occlusive disease with CLI of lower limbs at Kempegowda Institute of Medical Sciences and Research Centre, Bengaluru, India. All surgical procedures were done by a single vascular surgeon. The study period was a total of 48 months from June 2010 to May 2014.

Follow up period was for 24 months. The procedures included were open bypass surgery for both aortoiliac disease and infrainguinal arterial disease. Endovascular procedures included angioplasty with or without stenting. Emergency vascular surgical procedures done for acute limb ischemia such as thrombolysis or embolectomy were excluded.

Total number of procedures done study included 166 procedures done.

All patients had evidence of chronic CLI, defined as rest pain or ulcer/gangrene and were included in this retrospective cohort study. Preoperative, intraoperative, and follow-up information was available for all patients. Information was obtained from hospital records.

Selection of procedure type was based on discretion of the operating vascular surgeon. Procedure type has changed over the years and was based on advances and availability of endovascular technology and the primary surgeon's endovascular skills.

Ankle-brachial index (ABI) measurements and duplex scans were obtained before treatment. MR angiography was also done preoperatively. Postoperative follow-up (clinical examination, ABI measurements, and serial duplex ultrasound scanning) was conducted every week for first month followed by every month for 3 months every 3 months during the first postoperative year and every 6 months thereafter.

RESULTS: Majority of the patients in this study were male (94\%). This male predominance was consistent over all four years of the study period. Most of the patients presented in the fifth to the $7^{\text {th }}$ decade of life with the median age of 60 years.

All patients presented with chronic lower limb ischemia with critical limb ischemia. The main presenting complaints were, disabling claudication, rest pain, ulcers and digital gangrene. The underlying co morbid conditions included diabetes mellitus (84\%), smoking history (95\%), hypertension (92\%), hyperlipidemia (76\%), and cardiac disease (57\%). The incidence of diabetes as the main co-morbid condition has increased in recent years. However hypertension and atherosclerosis remains the main contributing factor to the disease process. The mean follow-up was 23 months.

A total of 166 procedures were done during this study period. Out of these, a total of 104 open surgeries and 62 endovascular procedures were performed. The open procedures performed were for both suprainguinal and infrainguinal lesions. Open procedures performed: Aorta-femoral (25) femoro-femoral (33) femoro-popliteal (46) bypass surgeries. Primary endovascular revascularization procedures included angioplasty alone (53\%) angioplasty + stenting (47\%). In the endovascular group, catheter-based angioplasty was performed at 8 iliac, 22 femoral, 9 popliteal, and 23 tibial or more distal arteries. 


\section{ORIGINAL ARTICLE}

Though the overall endovascular procedures performed was less, the percentage of endovascular procedures performed has steadily increased. From just over 5.8\% in June 2010 to May 2011 period to almost61\% in the last period (June2013 to May 2014) for distal arterial lesions (infra popliteal) the endovascular procedure rate was almost $95 \%$ in the last year.

The mean operating time, hospital stay, and morbidity rates were much higher in the open bypass surgeries as compared to the endovascular group.

Complications included local complications like wound infection, graft infection, pseudoaneurysm and graft occlusion which was much higher in the open bypass surgeries. There were two mortalities in the open bypass surgery group and 1 case of cerebrovascular accident in the post-operative period following open surgery.

In the endovascular group the common complications included re-occlusion (6.4\%) following angioplasty and1 instance of stent occlusion (1.6\%) There was significantly higher and the mean hospital stay was significantly longer with open surgery (10 days) compared with endovascular surgery (4days) $(\mathrm{P}<0.05)$.

The overall amputation rates have fallen over the years, from $11.7 \%$ in the first year to $2 \%$ in the last year.

Those patients that had endovascular procedures had significantly less pain in the postoperative period as compared to those that underwent open bypass surgeries. Especially those that underwent iliac angioplasties. The mean hospital stay and the time interval between discharge from hospital to return to work was significantly shorter (7 days) in endovascular group compared to the open group (20-30days).

DISCUSSION: Critical limb ischemia (CLI) has always been considered as a primary indication for bypass surgery. ${ }^{1-4}$ However, in recent years due to the advances in imaging techniques, angioplasty equipment, and endovascular techniques there has been a certain trend towards the less invasive endovascular procedures like angioplasty with or without stenting.

Many reports ${ }^{1-10}$ have supported the effectiveness of endovascular procedures in the treatment of patients with CLI with the added advantage of lower morbidity, hospital stay and cost.

Results of these endovascular procedures are comparable to those of surgical bypass in the management of patients with CLI.1,2,4,5,8-10 With newer improvements in endovascular technology, an increasing proportion of patients with CLI can be treated by endovascular procedures. ${ }^{1,4}$

Angioplasty could be the primary choice for the management of CLI because of better limb salvage rates and lower morbidity. There has been an increase in the number of iliac and infrainguinal angioplasty procedures performed for CLI.

Our study shows that the number of endovascular procedures done as primary procedures has dramatically increased over the last two years. Whereas the number of open surgical bypass procedures decreased. The changes in our results for treatment of CLI is similar to those of other reported institutional results. .-8 $^{5}$

Early intervention by either method seems to result in better outcomes. However, the endovascular approach seems to have a shorter hospital stay and lower morbidity and mortality. 


\section{ORIGINAL ARTICLE}

CONCLUSION: There is a trend towards endovascular revascularization procedures in our institute. Though initially because of technical difficulties and cost factor the number of open bypass surgeries in the initial years were more. However over the last 2 years there has been a shift towards endovascular procedures. These are associated with less morbidity and shorter duration of hospital stay.

Endovascular procedures are a now the safer and more effective option for revascularization of CLI and should be the primary choice for management. Whereas open bypass surgery could be reserved for those lesions that are not suitable for endovascular procedures or for those cases where attempts at an endovascular approach has failed.

\section{REFERENCES:}

1. Kudo T, Chandra FA, Kwun WH, Haas BT, Ahn SS. Changing pattern of surgical revascularization for critical limb ischemia over 12 years: Endovascular vs. open bypass surgery. J Vasc Surg. 2006 Aug; 44(2):304-13

2. Blair JM, Gewertz BL, Moosa H, Lu CT, Zarins CK. Percutaneous transluminal angioplasty vs. surgery for limb-threatening ischemia. J Vasc Surg 1989; 9:698-703.

3. Treiman GS, Treiman RL, Ichikawa L, Van Allan R. Should percutaneous transluminal angioplasty be recommended for treatment of infrageniculate popliteal artery or tibioperoneal trunk stenosis? J Vasc Surg 1995;22:457-65.te

4. Parsons RE, Suggs WD, Lee JJ, Sanchez LA, Lyon RT, Veith FJ. Percutaneous transluminal angioplasty for the treatment of limb threatening ischemia: do the results justify an attempt before bypass grafting? J VascSurg 1998; 28:1066-71.

5. Nasr MK, McCarthy RJ, Hardman J, Chalmers A, Horrocks M. The increasing role of percutaneous transluminal angioplasty in the primary management of critical limb ischemia. Eur J Vasc Endovasc Surg 2002; 23:398-403.

6. Anderson PL, Gelijns A, Moskowitz A, Arons R, Gupta L, Weinberg A, et al. Understanding trends in inpatient surgical volume: vascular interventions, 1980-2000. J VascSurg 2004; 39:1200-8.

7. Wieslander CK, Huang CC, Omura MC, Ahn SS. Endovascular workforce for peripheral vascular disease: current and future needs. J VascSurg 2002; 35:1218-25.

8. Sullivan TM, Taylor SM, Blackhurst DW, Langan EM 3rd, Cull DL, Carsten CG 3rd, et al. Has endovascular surgery reduced the number of open vascular operations performed by an established surgical practice? J VascSurg 2002; 36:514-9.

9. Adam DJ, Beard JD, Cleveland T, Bell J, Bradbury AW, Forbes JF, et al; BASIL trial participants. Bypass vs. angioplasty in severe ischemia of the leg (BASIL): multicentre, randomised controlled trial. Lancet 2005; 366:1925-34.

10. Salas CA, Adam DJ, Papavassiliou VG, London NJ. Percutaneous transluminal angioplasty for critical limb ischemia in octogenarians and nonagenarians. Eur J Vasc Endovasc Surg 2004;28:142-5. 


\section{ORIGINAL ARTICLE}

\section{AUTHORS:}

1. Ravikumar B. L.

2. Jose V. Francisco

\section{PARTICULARS OF CONTRIBUTORS:}

1. Associate Professor and HOD, Department of Vascular Surgery, KIMS, Bangalore.

2. Senior Resident, Department of General Surgery, KIMS, Bangalore.

\section{NAME ADDRESS EMAIL ID OF THE} CORRESPONDING AUTHOR:

Dr. Jose V. Francisco,

Flat No. A-701,

Spartan Heights,

16/17, Richmond Road,

Bangalore - 560025 .

Email: drjvfmenezes@gmail.com

Date of Submission: 12/07/2014. Date of Peer Review: 14/07/2014. Date of Acceptance: 19/07/2014. Date of Publishing: 28/07/2014. 